\section{Disposal of Radioactive Waste}

\author{
M. D. Hill, Harwell
}

National Radiological Protection Board
The disposal of radioactive waste is a topic which attracts considerable interest from both the scientific community and the general public and, in some countries has become a key issue in the continuing debate about the future of nuclear power. The purpose of this article is to provide a brief review of the information available on radioactive waste and disposal options and to outline those areas where research is required before disposal decisions can be taken. In this short article, it is not possible to deal with all types of radioactive waste and the discussion is restricted to highlevel waste, although the urgency to dispose of this type of waste is not so great as that for other types, in particular the large volumes of intermediate level waste which are now stored at nuclear sites. Disposal of high-level waste probably presents the greatest technical difficulties. In addition it has been the subject of greatest concern, for reasons which will become apparent.

\section{What is High-level Waste?}

The term "high-level waste" covers both irradiated nuclear fuel and the highly active liquid waste produced when spent fuel is reprocessed to recover uranium and plutonium. In most European countries, disposal of spent fuel is not being considered and hence this article will deal only with the high-level waste arising from fuel reprocessing.

Most of the activity present in the irradiated nuclear fuel eventually enters the high-level waste stream. This waste therefore contains a whole spectrum of radionuclides with a wide range of radioactive halflives. These radionuclides can be divided into two classes: fission products le.g. ${ }^{90} \mathrm{Sr},{ }^{137} \mathrm{Cs},{ }^{99} \mathrm{Tc}$ ) and actinides. The term "actinide" is used rather loosely in this context and this class of radionuclides includes uranium isotopes and the daughter products arising from the decay of all the heavy metal isotopes, as well as the true actinides. The exact radionuclide content of high-level waste obviously depends on the nature of the spent fuel, the conditions under which the fuel was irradiated, the efficiency of reprocessing and the time at which reprocessing occurred (i.e. the period over which the fuel remained in store after discharge from the reactor).
The inventory shown in Table 1 should representative, rather than indicating exact activities for any particular high-level waste sample. It can be seen from the Table that during the first few hundred years after reprocessing, the major portion of activity in high-level waste is due to relatively shortlived fission products, in particular ${ }^{90} \mathrm{Sr}$ and ${ }^{137} \mathrm{Cs}^{*}$. When these have decayed substantially, the actinides become more important in terms of their contribution to total activity, but there is also a major contribution from very long-lived fission products (e.g. ${ }^{99} \mathrm{Tc}$ ). It should also be noted that the activities of some actinide daughter products (e.g. ${ }^{226} \mathrm{Ra}$ ) increase with time after reprocessing, reaching a peak after times greater than the half-lives of their long-lived parent radionuclides.

The variation of the heat output of highlevel waste with time is shown in Fig. 1. It follows a pattern similar to that described above for total activity, with a fairly rapid decay during the first few hundred years when ${ }^{90} \mathrm{Sr}$ and ${ }^{137} \mathrm{Cs}$ are the dominant con-

* During the first 100 years after removal from the reactor, the total activity, being dominated by the shorter-lived fission products, falls rapidly, decreasing by a factor of 10 in the first 10 years and by a further factor of 10 in the next 90 years.

Table 1 - Inventory of the principal radionuclides in high-level waste $100 \mathrm{y}, 1000 \mathrm{y}$ and $10^{4} \mathrm{y}$ after reprocessing

\begin{tabular}{|c|c|c|c|}
\hline Radionuclide & $\begin{array}{l}\text { Activity at } \\
100 \mathrm{y}(\mathrm{Bq})\end{array}$ & $\begin{array}{l}\text { Activity at } \\
1000 \mathrm{y}(\mathrm{Bq})\end{array}$ & $\begin{array}{l}\text { Activity at } \\
10^{4} \mathrm{y}(\mathrm{Bq})\end{array}$ \\
\hline \multicolumn{4}{|l|}{$\begin{array}{l}\text { Fission } \\
\text { products }\end{array}$} \\
\hline $79_{\mathrm{Se}}$ & $1.4 \times 10^{10}$ & $1.4 \times 10^{10}$ & $1.3 \times 10^{10}$ \\
\hline $87_{\mathrm{Rb}}^{\circ}$ & $8.3 \times 10^{5}$ & $8.3 \times 10^{5}$ & $8.3 \times 10^{5}$ \\
\hline $90_{\mathrm{Sr}}$ & $2.4 \times 10^{14}$ & $5.6 \times 10^{4}$ & 0 \\
\hline $93 z_{\mathrm{zr}}$ & $7.0 \times 10^{10}$ & $7.0 \times 10^{10}$ & $7.0 \times 10^{10}$ \\
\hline $94 \mathrm{Nb}$ & $5 \times 10^{6}$ & $4.8 \times 10^{6}$ & $3.5 \times 10^{6}$ \\
\hline $99_{T c}$ & $4.4 \times 10^{11}$ & $4.4 \times 10^{11}$ & $4.3 \times 10^{11}$ \\
\hline $107_{\mathrm{Pd}}$ & $1.3 \times 10^{11}$ & $1.3 \times 10^{11}$ & $1.3 \times 10^{11}$ \\
\hline $113 m_{\mathrm{Cd}}$ & $8.4 \times 10^{9}$ & $2.3 \times 10^{-9}$ & 0 \\
\hline $121 m_{s n}$ & $1.4 \times 10^{9}$ & $5.3 \times 10^{3}$ & 0 \\
\hline $126_{\text {Sn }}$ & $2.0 \times 10^{10}$ & $2.0 \times 10^{10}$ & $1.9 \times 10^{10}$ \\
\hline $129_{1}$ & $1.1 \times 10^{9}$ & $1.1 \times 10^{9}$ & $1.1 \times 10^{9}$ \\
\hline $135_{\mathrm{cs}}$ & $1.4 \times 10^{9}$ & $1.4 \times 10^{9}$ & $1.4 \times 10^{9}$ \\
\hline $137 \mathrm{cs}$ & $4.0 \times 10^{14}$ & $4.1 \times 10^{5}$ & 0 \\
\hline $147_{\mathrm{Sm}}$ & $1.1 \times 10^{5}$ & $1.1 \times 10^{5}$ & $1.1 \times 10^{5}$ \\
\hline $151_{\mathrm{sm}}$ & $2.0 \times 10^{12}$ & $2.5 \times 10^{9}$ & 0 \\
\hline $152_{\mathrm{fu}}$ & $7.8 \times 10^{7}$ & 0 & 0 \\
\hline $154_{\mathrm{EU}}$ & $5.5 \times 10^{10}$ & 0 & 0 \\
\hline \multicolumn{4}{|l|}{ Actinides } \\
\hline $210_{\mathrm{pb}}$ & $3.3 \times 10^{4}$ & $1.6 \times 10^{6}$ & $6.8 \times 10^{7}$ \\
\hline $226_{\mathrm{Pa}}$ & $5.1 \times 10^{4}$ & $1.9 \times 10^{8}$ & $7.5 \times 10^{7}$ \\
\hline $228_{\mathrm{Pa}}$ & $1.6 \times 10^{8}$ & 4.1 & $4.3 \times 10^{8}$ \\
\hline $2277_{A C}$ & $6.0 \times 10^{5}$ & $6.9 \times 10^{5}$ & $1.3 \times 10^{6}$ \\
\hline $228_{\mathrm{Th}}$ & $3.3 \times 10^{5}$ & $6.1 \times 10$ & $4.2 \times 10$ \\
\hline $229_{\mathrm{Th}}$ & $2.0 \times 10^{4}$ & $1.9 \times 10^{6}$ & $1.7 \times 10^{8}$ \\
\hline
\end{tabular}

\begin{tabular}{|c|c|c|c|}
\hline Radionuclide & $\begin{array}{l}\text { Activity at } \\
100 \mathrm{y}(\mathrm{Bq})\end{array}$ & $\begin{array}{c}\text { Activity at } \\
1000 \text { y (Bq) }\end{array}$ & $\begin{array}{l}\text { Activity at } \\
10^{4} \mathrm{y}(\mathrm{Bq})\end{array}$ \\
\hline \multicolumn{4}{|l|}{$\begin{array}{l}\text { Actinides } \\
\text { Contd. }\end{array}$} \\
\hline $230_{\mathrm{Th}}$ & $1.4 \times 10^{6}$ & $9.9 \times 10^{6}$ & $9.6 \times 10^{7}$ \\
\hline $232_{\text {th }}$ & 1.6 & 4.0 & $4.3 \times 10$ \\
\hline $231_{\mathrm{pa}}$ & $6.3 \times 10^{5}$ & $6.9 \times 10^{5}$ & $1.3 \times 10^{6}$ \\
\hline $232 u$ & $3.2 \times 10^{5}$ & $5.6 \times 10$ & 0 \\
\hline $233_{\mathrm{u}}$ & $3.8 \times 10^{6}$ & $4.3 \times 10^{7}$ & $4.8 \times 10^{8}$ \\
\hline $234_{u}$ & $6.5 \times 10^{8}$ & $1.1 \times 10^{9}$ & $1.1 \times 10^{9}$ \\
\hline $235_{u}$ & $3.6 \times 10^{6}$ & $3.6 \times 10^{6}$ & $4.9 \times 10^{6}$ \\
\hline $236_{u}$ & $5.2 \times 10^{7}$ & $5.9 \times 10^{7}$ & $1.1 \times 10^{8}$ \\
\hline $238_{v}$ & $5.8 \times 10^{7}$ & $5.8 \times 10^{7}$ & $5.8 \times 10^{7}$ \\
\hline $237_{\mathrm{Np}}$ & $8.9 \times 10^{9}$ & $1.1 \times 10^{10}$ & $1.1 \times 10^{10}$ \\
\hline $236_{p u}$ & $1.4 \times 10^{-5}$ & 0 & 0 \\
\hline $238_{p u}$ & $1.2 \times 10^{12}$ & $5.5 \times 10^{9}$ & $7.2 \times 10^{-9}$ \\
\hline $239_{p u}$ & $6.9 \times 10^{10}$ & $8.6 \times 10^{10}$ & $1.7 \times 10^{11}$ \\
\hline $240_{p u}$ & $3.1 \times 10^{11}$ & $2.8 \times 10^{11}$ & $1.1 \times 10^{11}$ \\
\hline $241_{p u}$ & $2.8 \times 10^{11}$ & $6.7 \times 10^{9}$ & $3.3 \times 10^{9}$ \\
\hline $242_{p u}$ & $4.4 \times 10^{8}$ & $4.5 \times 10^{8}$ & $4.5 \times 10^{8}$ \\
\hline $241_{\mathrm{Am}}$ & $1.2 \times 10^{13}$ & $3.2 \times 10^{12}$ & $3.6 \times 10^{9}$ \\
\hline $242_{\mathrm{Am}}$ & $1.5 \times 10^{11}$ & $2.4 \times 10^{9}$ & $3.6 \times 10^{-9}$ \\
\hline $243_{\mathrm{Am}}$ & $7.6 \times 10^{11}$ & $7.0 \times 10^{11}$ & $3.0 \times 10^{11}$ \\
\hline $243 \mathrm{~cm}$ & $5.3 \times 10^{10}$ & $4.9 \times 10$ & 0 \\
\hline $244 \mathrm{~cm}$ & $1.7 \times 10^{12}$ & $1.3 \times 10^{-3}$ & 0 \\
\hline $245 \mathrm{~cm}$ & $7.3 \times 10^{9}$ & $6.8 \times 10^{9}$ & $3.3 \times 10^{9}$ \\
\hline $246 \mathrm{~cm}$ & $1.5 \times 10^{9}$ & $1.3 \times 10^{9}$ & $3.7 \times 10^{8}$ \\
\hline $247 \mathrm{~cm}$ & $4.5 \times 10^{3}$ & $4.5 \times 10^{3}$ & $4.5 \times 10^{3}$ \\
\hline $251_{C r}$ & $3.5 \times 10^{3}$ & $1.7 \times 10^{3}$ & 1.7 \\
\hline
\end{tabular}

1. Activities are given for the waste from 1 tonne PWR fuel

Notes

2. $18 \mathrm{q}=2.7 \times 10^{-11} \mathrm{Ci}$ therefore be regarded as typical and tributors, followed by a much slower decline during the period when longer lived actinides (e.g. ${ }^{241} \mathrm{Am}$ ) control the thermal output.

\section{Waste Management and Disposal}

All high-level waste is currently stored, most of it in liquid form, in cooled tanks specially constructed for the purpose. Although this situation is acceptable at present and will continue to be so in the short term, it is clear that long term management procedures need to be established in order to ensure that the risks associated with high-level waste are kept to acceptable levels.

The elements of a general waste management strategy are shown schematically in Fig. 2. In the case of high-level waste, there is now widespread agreement that the first, conditioning, step should consist of conversion of the waste to a solid form. (At an early stage in waste management research it was suggested that it might be possible to dispose of liquid high-level waste directly by injecting it into rock formations, but this option has been rejected on both technical and safety grounds). Various solidification processes have been proposed but the one which has received most attention in Europe and which has been demonstrated on an industrial scale (at Marcoule in France) is vitrification. In this process, the liquid waste is mixed with the constituents of borosilicate glass at high temperature to produce cylindrical glass blocks.

At proposed block sizes $(0.4 \mathrm{~m}$ diameter and $1.5 \mathrm{~m}$ high) and levels of waste incorporation ( $12.5 \mathrm{wt} \%$ radioactive oxides is typical) about 2,400 blocks, each weighing $490 \mathrm{~kg}$, would be produced for each 100 $\mathrm{GW}(\mathrm{e})$ of electrical energy generated by nuclear power. To put this in perspective, 


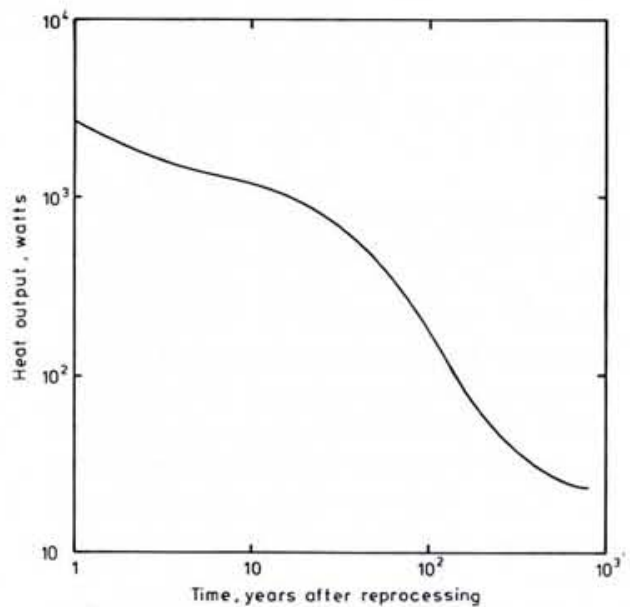

Fig. 1 - Thermal output of a block of vitrified high level waste weighing a little less than half a ton.

the quantity of electrical energy that will be generated in the UK from now until the year 2000 is estimated to be $330 \mathrm{GW}(\mathrm{e}) \mathrm{y}$.

The glass blocks are formed in steel canisters, so the packaging and conditioning steps can be considered to have been carried out in one operation. However, further packaging (for example placing the cylinders in thick metal overpacks) may take place either prior to storage or prior to disposal, depending on the storage and disposal options selected.

Once the waste has been solidified, the next stage in the management strategy will be to store it for a period to allow the heat output to decay, and thus facilitate further handling and disposal. The length of storage period required, depends to a large extent on the disposal option chosen, but many other factors will affect this decision. It can be argued, for example, that storage of the waste is needed in order to allow time for further research into disposal options. Some would take the more extreme view that high-level waste should be stored indefinitely, because it is unlikely that any disposal option will be shown to be acceptable. At the opposite end of the spectrum of views, others would advocate disposal of high-level waste as soon as it is technically feasible.

The decision on the period for which high-level waste should be stored is therefore particularly difficult and complex, in which more than technical questions are raised. At this stage in the research into high-level waste management, there seems to be some consensus that the storage period should be somewhere between 30 and 100 years, but there is considerable uncertainty associated with these estimates and in some European countries the option of indefinite storage has not been completely ruled out.

Assuming that indefinite storage is not acceptable, the final step in the management strategy is disposal. The distinction between storage and disposal is essentially one of intent: in the case of storage, the in- tention is that the waste will be retrieved at some later date, whereas disposal implies abandonment with no intention to retrieve, although it may be technically possible to do so.

Of the many disposal options which have been proposed for high-level waste, three appear to be feasible using current technology and upon which research effort is being devoted in European countries. These options are: emplacement in deep geologic formations on land, emplacement on the bed of the deep ocean or emplacement under the bed of the deep ocean. There are fairly large differences in the emphasis of the research programmes of various countries: some concentrate on one very specific option (for example disposal in a particular type of rock formation), while others are pursuing a more broadly based approach. In the UK, for example, the ocean and land disposal options are receiving approximately equal research effort, and several types of rock formation are being considered in the case of geologic disposal. Although the research carried out in various countries differs in scope and detail, it all has the common objective of providing sufficient information to decide whether disposal options are acceptable. One of the major factors in these decisions is the predicted radiological impact of disposal options and most of this research is therefore concerned with obtaining the data needed for radiological assessments.

\section{Radiological Assessments}

Assessments of the potential radiological impacts of high-level waste disposal options have three major components. First, the mechanisms by which radioactivity may be released from the disposal site into the environment are determined. This involves identifying the events and processes which could directly cause a release or could influence the rate at which the release occurs. The complexity of this part of the assessment varies from one option to another. For example, in assessing the radiological impact of disposal on the bed of the deep ocean, it is clear that corrosion of the waste canisters by sea water, followed by leaching of radionuclides and dispersal in the oceans is certain to occur. However, for geologic disposal the situation is more complex, with natural events such as seismic activity, repository-related processes such as thermal effects on rocks, and human activities such as future exploratory drilling for mineral resources, to be considered.

The second stage of the assessment consists of estimating the probabilities of occurrence of the events and processes identified in the initial part. Again the complexity and degree of difficulty of this part of the assessment varies between options. In the case of geologic disposal, for example, estimation of the probabilities of occurrence of natural events and processes is required. This is not an easy task since it involves prediction of the times and frequencies at which geologic events may occur and predictive geology is a relatively new field of research.

The third component is the evaluation of the radiological consequences of releases. This involves the use of mathematical models to calculate the rates of release of radionuclides from the waste (for example, by leaching), their rates of transport through the environment (for example, the oceans) and the eventual radiation doses to man. In general, it is necessary to evaluate the consequences of a release as a function of both the time at which the release occurs and the time after the release.

From the results of assessments it is possible to build up a picture of the radiological risks associated with disposal options and hence to provide an input to waste management and disposal decisions. The derivation and analysis of these results clearly poses considerable difficulties, especially in view of the very long time periods involved and the uncertainties associated with predictions over these timescales. For these reasons, in most of the preliminary assessments of disposal options (see examples in bibliography) only the more likely release situations have been considered and simple assumptions have been made, such as the persistence of present-day conditions over the whole of the time period of the assessment. These types of study are valuable because they give an indication of potential risks and hence enable a decision to be taken as to whether a disposal option is worthy of further investigation. Their primary use, however, is in identifying research priorities, since by analysing the sensitivity of the results to variations in assumptions and

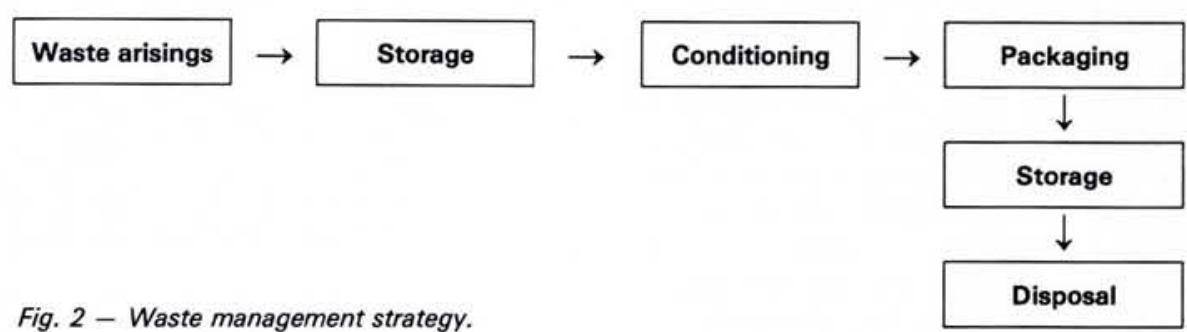


parameter values, the areas where improvements in data and modelling are most urgently required can be determined. As research proceeds, assessments can be updated until eventually there is sufficient confidence in the results for disposal decisions to be taken.

\section{Current Status of Research}

For the purpose of this review, the research on high-level waste disposal options can be divided into the following subject areas: waste form, waste package, engineered barriers and the disposal environment. The most complex of these, and the one to which most effort is devoted, is the disposal environment. Drilling programmes aimed at characterising potentially suitable rock formations are now underway in many countries. The rock types under investigation include granites, basalts, clays, shales and salt. In addition to the field studies, laboratory and in situ experiments are being carried out in order to determine rock properties such as response to thermal stress and capacity to retard the migration of radionuclides with groundwater. For the ocean disposal options, research is directed towards investigating sediment properties, to the development of realistic models of ocean

\section{University of Geneva}

The Physics Department of the University of Geneva is seeking an Associate Professor of Applied Physics

(problems of energy).

Teaching duties:

- organisation of courses in applied physics in the Physics Department, and

- participation in the courses given by the University Center for the Study of Energy Problems.

Applications are to be submitted before June 30, 1981 to:

Prof. Greppin, Dean Faculté des Sciences

Université de Genève, 20 quai Ernest-Ansermet

$\mathrm{CH}$ - 1211 Geneva 4, Switzerland

circulation patterns and to obtaining more detail of the rates of transfer of radionuclides through marine food chains.

Research on waste forms, waste packages and engineered barriers (e.g. the materials which may be used to backfill geologic repositories or to surround waste canisters) is primarily concerned with the prediction of behaviour under disposal conditions. For example, the results of leach tests on vitrified high-level waste under laboratory conditions have been available for some time, but evaluation of the rates of release of radionuclides by leaching under conditions of low groundwater flow, or through access by seabed sediment pore water, is at an early stage. Thus although research has been in progress for several years, more is required in order to provide all the information needed for comprehensive risk assessments.

The conclusion to be drawn from the available knowledge is a simple one: there are enough data to conclude that the disposal of high-level waste is technically feasible, but there is as yet insufficient information to demonstrate that proposed disposal options are acceptable, and to enable a choice to be made between the various options.

The Board of Governors of the Eindhoven University of Technology, Eindhoven, The Netherlands, wishes to announce a vacancy for an

\section{ORDINARY PROFESSOR OF THEORETICAL PHYSICS (M/F)}

The appointee will work in the Theoretical Physics Group of the Department of Physics, where at present research is done in the fields of methods of mathematical physics, quantum mechanics and theoretical plasma physics.

The professor appointed will be expected

- to have a field of interest and research which enables him to maintain a fruitful collaboration in the sphere of teaching and research with both the other professors in the group and the existing staff.

- to have a profound knowledge of general physics which will allow him to co-operate as well with other groups of the department, engaged in both experimental and applied physics.

- to participate in the task of the department in the field of teaching theoretical physics to third year students and senior undergraduates. He will furthermore be expected to give guidance to work of students finishing their courses and graduate students working on a Ph.D. thesis.

- to take part in administrative activities of the group or - if required - of the department.

Letters of application, together with a detailed curriculum vitae and list of publications as well as the names and addresses of qualified persons who would be prepared to give some personal and scientific background information should be addressed, with the indication V 4391. ., to the

Dean of the Department of Physics, prof.dr. O.J. Poppema,

Technische Hogeschool Eindhoven, Postbus 513.

$5600 \mathrm{MB}$ Eindhoven, The Netherlands.

Applications are awaited within four weeks after the date of appearance of this advertisement.

Additional information can be obtained from the Chairman of the Selection Committee, prof.dr. D.A. de Vries,

Technische Hogeschool Eindhoven, Postbus 513,

5600 MB Eindhoven, The Netherlands (Tel: (40) 472250 ).

Those wishing to draw the committee's attention to potential candidates are kindly requested to communicate with the Chairman of the Selection Committee.

\section{BIBLIOGRAPHY}

1. "Underground Disposal of Radioactive Wastes", Proceedings of an International Symposium, Otaniemi, 2-6 July 1979 (IAEA, Vienna) 1980.

2. "Radioactive Waste Management and Disposal", Proceedings of First European Community Conference, Luxembourg, 20-23 May 1980 (Harwood Academic Publishers) 1980.

3. "Impacts of Radionuclide Releases into the Marine Environment", Proceedings of an International Symposium, Vienna, 6-10 October 1980 (IAEA, Vienna) in press.

4. Hill M.D., "Analysis of the Effect of Variations in Parameter Values on the Predicted Radiological Consequences of Geologic Disposal of HighLevel Waste", NRPB-R86 (National Radiological Protection Board, Harwell) 1979.

5. Burkholder H.C., "Waste Isolation Performance Assessment - A Status Report", ONWI -60 (Battelle Memorial Institute, Office of Nuclear Waste Isolation, Columbus, Ohio) 1979.

6. "Handling of Spent Nuclear Fuel and Final Storage of Vitrified High Level Reprocessing Waste", Karnbranslesakerhet (KBS) Project, Stockholm, 1977.

7. Talbert D.M. (ed.), "Seabed Disposal Programm Annual Report, January-December 1977", SAND-78-1359 (Sandia Laboratories, Albuquerque) 1979.

8. Grimwood P.D. and Webb G.A.M., "Assessment of the Radiological Protection Aspects of Disposal of High-Level Wastes on the Ocean Floor", NRPB-R48 (National Radiological Protection Board, Harwell) 1976. 